\title{
Research / Design and Academia
}

\author{
Susanne Hauser
}

Editorial Summary: In her contribution »Research / Design and Academia « Susanne Hauser discusses institutional developments and changes in academia since the 1990s, alongside which disciplinary frontiers and thematic as well as methodological approaches have been re-examined and reorganized. She highlights systemic differences in funding as well as uneven particularity in methodological attempts as fundamental reasons for the different recognition of e.g. practice-based and traditional types of academic research in architecture. Against the background of her personal academic foundation in cultural studies, she traces the genesis of the architect's education as a generalist, responsible for design and conception, creation and making. Considering the specific potential of design, she argues for the recognition of designing as a specific approach to the generation of knowledge. [Katharina Voigt]

Keywords: Design; Knowledge; Architectural Education; Academic Institutions; Environmental Models; Aesthetics; Concrete Object; Criticism.

One of the most discussed issues of the last 25 years in cultural studies was and still is - the notion of knowledge. This was not the case because the humanities were in an exceptional state of crisis, but there were several changes able to disturb the on-going business as usual. One of these developments was a change merely due to political decisions based on neoliberal concepts and convictions. They inspired a redefinition of political aims, of public interest, and of public spending. Public institutions, such as universities, were not funded anymore beyond the absolutely necessary means to keep up their sometimes newly - and usually more restrictedly - defined main function, in the case of universities: education, not in the sense of Bildung (education) but in the sense of Berufsbildung (practitioner's training). The new policy of less money for more economically defined aims came along with two new practices. One of them was the funding of project-based research that established the necessity of permanent competition even in fields that were not able to compete in an economic sense. The other practice entering universities during the 1980s and implemented till the turn of the millennium the latest 
was the practice of permanent evaluation. The combination of these three changes - less public funding for the basic needs of universities, the generalization of project-based research and funding, and the implementation of more or less strict and more or less biased evaluation modes - produced impressive changes in many fields of research. Probably only those branches of science able to define future applications of their research were exceptions as they were already accustomed to project-based funding, externally controlled competitive situations, and to commissions. The process of reorganizing academia had, and still has, locally and nationally specific outcomes, some of which are ambivalent. In Germany, for example, the changes triggered productive interdisciplinary cooperation within universities, while individual research, widely characteristic for the humanities, tended to be less appreciated than collective endeavors. Groups, whose members had never dreamed of working together within huge organizational structures, entered the scene to look for project funding and to produce »knowledge«, preferably proven by dissertations, $\mathrm{PhDs}$, and publications.

For me, as a researcher in architecture with a background in cultural studies, it became evident that the topic of knowledge in architecture had to be explored (cf. Hauser 2005:21-27). ${ }^{1}$ I want to stress again though, that it was not only the discipline of architecture in academic settings that had to change some basic convictions and practices; various disciplines were challenged in their academic habits. The first quest for research in architecture, however, similar to the quest for research in the arts - belonged to a wider restructuring endevor. It redefined the field of accepted academic knowledge and the realm of what was accepted as academic research. Obviously, the production of knowledge meeting such standards was not one of the key features that architects relied on when they described their practice, and it was not what architecture schools usually saw or even still see as the core of their teaching ambitions. The most defining practice for architects and students in architecture was the practice of designing, the production of new concepts and designs. And obviously, the process of designing, the key activity taught in schools of architecture, clearly did not meet academic standards as such. It is evident that there was a challenge in entering the special activity of designing into the realm of accepted approaches to research. Today, I believe that

1 See also the doctoral program »Knowledge in the Arts« (2012-2021), University of the Arts Berlin: https://www.udk-berlin.de/forschung/temporaere-forschungseinrichtungen/dfggraduiertenkolleg-das-wissen-der-kuenste/. 
we are on our way to accepting that there are different kinds of knowledge in academia - and that the very special type of knowledge production defining architecture is an important part of it.

This notion has depended, and still depends, on institutional conditions. There exist architecture departments within schools or faculties of art and design with little affinity to social and cultural studies. Furthermore, there are architecture departments in technical colleges - in Germany Fachhochschulen, in Britain polytechnics. Some architecture schools are close to or a part of engineering faculties, whereas others evolved from beginnings in the art history faculty of universities. Architecture departments and schools differ widely in their approaches to the field of relevant academic issues for future architects, in their attitudes toward the arts, technology, and the humanities - and accordingly to research in general. Nevertheless, they all tend to teach expertise and capability in designing.

So I understand designing as the essential practice in architecture., This motivates my plea for the acceptance of this practice as the distinguished and characteristic contribution of architecture to research and to the production of academic knowledge. I came to this conclusion some 20 years ago when I analyzed two landscape designs and became interested in the process of their development (see Hauser 2006, in: Hess-Lüttich (ed.): 95-104). Both designs implied answers to a variety of heterogeneous questions, among them decisions about materials to be used, about structures to be built, but also answers to fundamental questions like how to define and present the relations of "man« and »nature«. I realized how many different aspects had been dealt with during the design processes, while the results, the finished and finally realized designs, were undeniably entities in their own right. I began reflecting the process of designing as an operation dealing with heterogeneous aspects leading to a synthesis, as well as about the practice of designing as a cultural technique (see Hauser 2013, in: Ammon/Froschauer (eds.):363-381). In a first and tentative approach, I proposed to read the two inspiring landscape designs as »environmental models« (»Umweltmodelle«). The intention was to indicate the wide scope of their topics and their potential impact. I coined the expression in reference to Jacob von Uexküll's semiotic concept of the »Umwelt (von Uexküll 1956: 103-159). Uexküll's description of sign-processes as bonds of any living being and the - for this being - relevant traits of its surroundings seemed to offer a promising approach to understanding the manifold aspects of our permanent individual, collective, and societal exchange with our environment. The concept of the environment as 
a sign-based relation implied the idea that designs were readable as complex offers of sensations, communications, and activities: as new proposals of environmental models. I liked the metaphor and the assumption of a multifaceted relatedness of designs in their elaboration and emergence as well as in their built manifestations and assumed that this perspective provided an adequate approach to the further analysis of the manifold aspects of architecture and landscape architecture.

A second helpful reference for the understanding of designs was due to the observation that we tend to talk about designs as single entities emerging in a process. Presumably, this process starts quite often with a first idea, a first sketch pointing to a future result meeting the aims or the initial intentions of the design (cf. Cross 2004: 427-441). ${ }^{2}$ In the course of the process, a variety of decisions about future sensations, communications, and exchanges will be molded into one single result, ultimately called »the design«. This observation led me to Ernst Cassirer's suggestive metaphor of the »crystallization foci«. This is how he understands, in his Philosophy of Symbolic Forms, the origins of conceptual formations, the beginnings of the separation and organization of an unorganised field into meaningful structures, and thus the beginning of language (Cassirer 1990: 135). His vision of a slowly stabilized core and its characteristic structure born out of a non-ordered potentiality provided a useful image for the understanding of the emergence of designs in architecture or landscape architecture, even if this image did not reflect the complexity of the knowledge and methods involved.

I came to the conclusion that at the beginning of a design process, architects or designers do not know in detail how to get their final result. Even the number of aspects to be explored and their relations cannot be listed conclusively. An enumeration of tasks and aspects would reduce any analytical approach to the processing of a checklist and neglect the possible relations of different issues. If we understand designing as an exploratory activity with the potential to create new options, it is clear that operating via checklists is not the defining aspect of this activity. Design processes start with incomplete knowledge and, at least in principle, questionable methods. Without the intention of change, of challenging rules and routines, there is no need for a process whose most important quality is its capacity to produce new

2 Cross argues that experienced architects and designers tend to solve and analyze the "problems " (of a certain design) at the same time and produce ideas and concepts already at a very early stage of their acquaintance with a certain project. 
results. Doing a design may imply revisions of established knowledge, the questioning of trusted rules and regulations, and the necessity to go beyond common or familiar methodological approaches; Research is required and an expected part of the process. The idea of completeness in the acquisition of useful or necessary knowledge for a design, however, is specific and in so far of interest: Any research will be pursued to exactly the extent that allows for the continuation of the design process. Not each and every aspect of a design has to be tackled with the same curiosity or intensity. Completeness in the sense of conducting exhaustive research on decisive issues is not necessary for the completion of a certain design. The only criterion for the successful closure of the necessary research activity is whether the required answers to the open questions are found according to the unfolding aims of the unfolding design process.

The relevant issues in architectural designs are manifold. They include, for example, the necessity of satisfying basic needs such as shelter from weather and climatic conditions; the spatial organization of social processes; mechanic and constructive questions; aesthetic qualities and choices of materials; functional options such as the adaptability to specific social situations; sustainability; ecological consequences and their monitoring or measuring; financial outcomes of investments. And there may be many more issues at stake. The aspects or layers deemed relevant for a design follow different types of logic. They do not belong to or refer to just one societal subsystem systems theory could identify. This means that their expressions in designs cannot be evaluated according to the same rules, although all of these aspects are involved in the definition of one single design. Thus, the key qualification in architectural design may be described as the ability to synthesize heterogeneous issues, different kinds of knowledge including practices, skills, and aptitudes, and to turn them into one single option. This requires a highly qualified and yet non-specialized approach also implying decisions on sensual matters, as designs propose visual, tactile, and auditory sensations.

Here I want to take up and reinforce the subject of the role of architecture within academic institutions: I assume that the generalist and universal approach and the close affinity of design processes to sensual options are responsible for the unclear status of architecture and architectural knowledge in academic institutions such as universities, colleges, art schools, and academies. As I mentioned before, schools of architecture are found within all of these institutions. It is interesting though, to observe 
that they all seem to be exceptional compared to their neighboring faculties. Architecture is too artistic to be seen as an obviously serious engineering discipline in technical universities; architecture offers too many pragmatic or profitable solutions for pragmatic problems to be fully accepted as an art in art schools; it is too involved with and dependent on engineering concepts and approaches to impress the humanities still surviving in classic universities; and colleges providing merely practice-oriented courses are observed suspiciously by architects from other schools as they may support less ambitious and more opportunistic habits in building processes. This position of architecture schools among, above, and between other disciplines and practices is a challenge and a special condition resisting specialization in methodology as well as in knowledge. This position is due to the non-restricted approach necessarily implied in seriously innovative work.

This brings me to the question as to how far specialization is an important issue in study programs addressing future architects. Still in 2006, Ivar Holm described the pursuit of »holism« as a guiding principle and thus a regulative idea for architectural education. It should be noted that Holm interpreted the relevance of this concept as a widely shared conviction, not as a fact. Used in this context, however, holism tends to imply »an all-inclusive design perspective which is often regarded as somewhat exclusive to the two design professions « (architecture and industrial design) distinguishing them from other professions involved in design projects (Holm 2006: 173). According to Holm, architectural students and students of industrial design are trained to develop "a « design as a single whole, as a project encompassing all possible traits, and to understand these traits as necessarily linked. They also learn to see themselves as the "natural person to be in charge of the design process « (Ibid.: 174), a definition of the architect's position that has been seriously challenged through economic, technological and conceptual developments since the 1980 s (e.g. Anstey et al. (eds.) 2007). Holm contrasts this attitude with the usual approach to education in the engineering disciplines. According to his observations, young engineers learn how to solve single problems on a functional basis and are not expected to deal with the general »holistic« perspective (Holm 2006: 173).

»Holism« may also find a different interpretation that stresses the idea of a perfect control of designs. The necessary precondition is, as Holm realizes, the identification of all possible questions, aspects, and relations of a certain design or of designing in general. Holm quotes Harold G. Nelson and Erik Stoltermann who indeed came to this conclusion (Nelson/Stoltermann 
2003). This »holistic approach requires a complete set of tools or at least a complete set of criteria and standards that only a complete and final "system « can provide. Its ideal expression would be a single tool defining the ends and means of the process of designing. This option challenges the idea of the architect's professional role as well as the idea of designing as a cultural technique with the unique potential to question even its own methodology (see »Einleitung« in: Gethmann/Hauser (eds.) 2009, 9-16). It may also be a form of bringing architectural research to an end before any coherent position on architectural research has been developed.

The question of whether and when a certain design is finished is varied and debatable. The answer depends on intellectual and local contexts and leads back to the idea of the specific environmental model as well as to the thesis that research processes - and also their traces in designs too - depend on aims and attitudes: There is no general rule explaining how and when designs are finished, and they tend to be revised again when it comes to building. In any case, it is by decisions that design processes come to their end. The diagnosis that a certain design is finished, at least for the present moment, is usually backed through different arguments. They may be subject to lengthy discussions. As designs include answers to many heterogeneous questions, it is not surprising that the criteria for these decisions are manifold. Some among the many possible criteria refer to norms, to usual practices of crafts and engineering, and to other trusted disciplines such as mathematics or biology. These criteria seem to be the least problematic, especially if they are based on practices usually seen as reliable, such as measuring or calculating. Functional qualities, the conviction that pragmatic aims are met and that usability will be achieved through the design in question, are also important. Then there is the evaluation of designs according to less welldefined aesthetic criteria such as suitability, unity, and coherence, qualities associated with sensual satisfaction. ${ }^{3}$ The results of design processes have to be seen as aesthetic accomplishments and have to show an aesthetic necessity, yet these criteria are not easily explained through generally accepted standards. Designers and trained critics, however, seem to be able to agree on the answer to the question of whether a design shows these qualities of suitability, coherence, or fitness and is worth being accepted as completed in this respect too - even if the evaluations may differ in other aspects.

3 These criteria may still be summed up in (interpretations of) Vitruvius' definition of the key requirements in building: firmitas, utilitas, and venustas. 
There are several criteria for the judgment of finished architectural designs. They differ from judgments of other results of academic activity and of other approaches to research. Among the desired qualities are what we may call "fitness « in the sense of fitting into a certain condition or in the sense of making a certain condition fit the new design and »suitability«, or »coherence« of a design for the buildings, urban structures or open spaces at stake. Nelson Goodman introduced the "fit" or "fitness" as the ultimate criterion for a critique of a work of art (Goodman 1978: 138; Goodman 1981: 264). I mention this notion, as there is an interesting relation between this approach to the judgment of art and the judgment of results in the development of technology. Goodman's state of »fitting « and the »concrete technical object « in the sense of Gilbert Simondon's term are related concepts in so far as both mark the (preliminary) end of a productive process. Simondon's essay on the philosophy of technology was an innovative contribution to the long European history of philosophical thought concerning concepts of wholeness and unity. ${ }^{4}$ According to Simondon, the concrete technical object is completed when the manifold aspects it reflects and the different "forces" it contains are brought together in such a way that the involved powers and functions do not disturb each other, but result in a new arrangement merging the synergies of all implied elements and functions in a harmonious way (see the first chapter of Simondon 2016). This seems to be a useful description of designs too.

This is also quite important for the question of the acceptance of designs as relevant results of academic research: It is interesting to note that Gilbert Simondon and Nelson Goodman do not attempt to fully explain what their respective ideal integrations in a work of technology or in a work of art may mean. Nor do they assume that anyone, including the designers themselves, is able to understand the complexity involved. Simondon's "concrete object» is not completely analyzable by its makers, and the same applies for the works of art and architecture discussed by Nelson Goodman and Catherine Z. Elgin (see Goodman/Elgin 1988: 44). In this respect, the philosopher of technology and the philosophers of signs and representations agree - which I consider highly interesting, as both argue using quite a transgressive manner in the definition of their objects.

4 The idea of an inseparable whole, a complex unit, and a single integrated object, has of course been a traditional subject in reflections on art and aesthetics since the 18th century; e.g. Dällenbach/Hart Nibbrig (eds.) 1984. 
These criteria, however, cannot be supported through any classic methodology of the sciences or through the hermeneutic approaches of the humanities: The basis for these judgments is aesthetic ability, training, and extensive experience. Whether these abilities survive in present academic institutions is one of the very relevant issues at stake. As long as architecture is understood "as an aesthetics-based network of practices of environmental transformation « (Arteaga 2016, in Arteaga (ed.): 8), the idea of a final definition of design will not be the final idea in designing and the creation of models for new and enriching environments - and may, as I hope, contribute as such to the range of academic research and knowledge production. ${ }^{5}$

5 This text is partly based on a first version and its discussion in Arteaga 2020: 330-350. My thanks go to the authors of the book, especially to Alex Arteaga, Mika Elo, Lidia Gasperoni, and Jonathan Hale. 


\section{References}

Anstey, Tim/Grillner, Katja/Hughes, Rolf, eds. (2007): Architecture and Authorship, London: Black Dog Publishing.

Arteaga, Alex (2016): »Architecture Without Walls: An Introduction«, in: Alex Arteaga/Boris Hassenstein (eds.), Architecture Without Walls, Berlin: Errant Bodies Press, 4-12.

Cassirer, Ernst (1990 [1929]): Philosophie dersymbolischen Formen, Dritter Teil. Phänomenologie der Erkenntnis, 9th edition, Darmstadt: Wissenschaftliche Buchgesellschaft. - English translation: The Philosophy of Symbolic Forms: Vol. 3: The Phenomenology of Knowledge, transl. by Ralph Manheim, New Haven: Yale University Press, 1965.

Cross, Nigel (2004): »Expertise in Design: An Overview«, in: Design Studies 25(5), 427-441.

Dällenbach, Lucien/Nibbrig, Christiaan L. Hart, eds. (1984): Fragment und Totalität, Frankfurt: Suhrkamp Verlag.

Gethmann, Daniel/Hauser, Susanne eds. (2009): Kulturtechnik Entwerfen, Bielefeld: transcript Verlag.

Goodman, Nelson (1978): Ways of Worldmaking, Hassocks, Sussex: The Harvester Press.

Goodman, Nelson (1981): Languages of Art, Hassocks, Sussex: The Harvester Press.

Goodman, Nelson/Elgin, Catherine Z. (1988): Reconceptions in Philosophy \& Other Arts and Sciences, Indianapolis/Cambridge: Hackett Publications.

Hauser, Susanne (2005): »The Knowledge of Architecture - an Essay/Das Wissen der Architektur - ein Essay«, in: Graz Architectural Magazine 2, 21-27.
Hauser, Susanne (2006): »Modelldenken in den Wissenschaften «, in: Dialektik 1997/1, 105-118. - English translation: »Environmental Models - Landscape Planning and New Descriptions of Nature«, in: Ernest W. B. Hess-Lüttich (ed.), Eco-Semiotics, Tübingen: Francke, 95-104.

Hauser, Susanne (2013): »Verfahren des Überschreitens. Entwerfen als Kulturtechnik«, in: Sabine Ammon/ Eva Maria Froschauer (eds.), Wissenschaft Entwerfen. Vom forschenden Entwerfen zur Entwurfsforschung der Architektur, Munich: Wilhelm Fink Verlag, 363-381.

Hauser, Susanne (2020): »The Ends of Design«, in: Alex Arteaga (ed.), Architectures of Embodiment. Disclosing New Intelligibilities, Berlin: Diaphanes, 330-350.

Holm, Ivar (2006): Ideas and Beliefs in Architecture: How Attitudes, Orientations, and Underlying Assumptions Shape the Built Environment, Oslo: Oslo School of Architecture and Design.

Nelson, Harold G./Stoltermann, Erik (2003): The Design Way: Intentional Change in an Unpredictable World: Foundations and Fundamentals of Design Competence, Englewood Cliffs, N]: Educational Technology Publications.

Simondon, Gilbert (1958): Du mode d'existence des objets techniques, Paris: Aubier. - English translation: On the Mode of Existence of Technical Objects, transl. by Cécil Malaspina/John Rogove, Minneapolis, MN: Univocal Publishing, 2016.

von Uexküll, Jakob (1956):

»Bedeutungslehre«, in: Jakob von Uexküll/ Georg Kriszat, Streifzüge durch die Umwelten von Tieren und Menschen. Bedeutungslehre, Reinbek bei Hamburg: Rowohlt, 103-159. 